\title{
Impression Marketing as a Tool for Building Emotional Connections in the Public Administration Sphere
}

\author{
Nataliia Likarchuk ${ }^{1}$, Olha Andrieieva ${ }^{2}$, Daria Likarchuk ${ }^{3}$, Andrii Bernatskyi ${ }^{1}$ \\ ${ }^{1}$ Department of Public Administration, Educational and Scientific Institute of Public Management and Public Service, \\ Taras Shevchenko National University of Kyiv, Kyiv, Ukraine \\ ${ }^{2}$ Department of International Information, Educational and Scientific Institute of International Relations, Taras \\ Shevchenko National University of Kyiv, Kyiv, Ukraine \\ ${ }^{3}$ Department of International Relations, Kyiv National University of Culture and Arts, Kyiv, Ukraine \\ Correspondence: Nataliia Likarchuk, Department of Public Administration, Educational and Scientific Institute of Public \\ Management and Public Service, Taras Shevchenko National University of Kyiv, 04050, 12/2 Akademik Romodanov Str., \\ Kyiv, Ukraine. E-mail: n.likarchuk@nuos.pro
}

Received: December 13, 2021

Accepted: January 15, $2022 \quad$ Online Published: January 25, 2022

doi:10.11114/smc.v10i1.5463

URL: https://doi.org/10.11114/smc.v10i1.5463

\begin{abstract}
Marketing is an extremely dynamic and intensive phenomenon, and the transformations taking place in the modern market paradigm cause the emergence of impression marketing in different spheres including the political one. This article is aimed at the analysis of the marketing of impressions as a tool in the political sphere. Emotions that influence making decisions were identified. Ukrainian post-Maidan society was studied and the population reaction to President V. Zelensky's emotional style of communication was analysed. As the result of the study, it was found that emotional marketing affects a person's feelings, their emotional state and is associated with the creation of positive associations. It can be stated that modern politics is characterized by components of attraction, theatricality, entertainment. Action management in Ukrainian political space is studied and such examples as speeches by politicians, parliamentary sittings, arrests and searches of businessmen are provided. The general perception of the president was evaluated and it was found that the emotional feelings of the population are almost polar. It was concluded that emotions are an indicator of the political situation in the country and in Ukraine, in the political sphere, fear is one of the decisive emotions which, in particular, plays a mobilizing role. Thus, impression marketing is a powerful tool for adjusting the electorate to the emotional rhythm of information perception.
\end{abstract}

Keywords: emotional marketing, product nature, traditional marketing, public administration, Ukrainian society

\section{Introduction}

Peculiarity of emotional marketing is a profound impact on the individual (consumer / customer / electorate). As it is known in classical marketing, the decision-making process is aimed at rational thinking, while in emotional the impact is directed at the subconscious, especially in areas where the product is filled with emotional component (in particular, all show projects that overwhelm the political sphere). The modern consumer rarely uses rational thinking because goods are often similar to each other and can still perform basic functions. Given the above, a person is looking for an emotional component that would complement or fill the product (and political one as well) with the additional effects that may excite them. It is possible to capture the consumer's attention, to "surprise" them by offering extraordinary impressions, emotions, ideas, views, judgments (Cervera et al., 2000).

Special technologies of emotional marketing are such modern mechanisms that are associated with social networks, virtual reality, receiving bonuses, the Internet, quality video content. It is especially important to evoke positive emotions, "bringing" emotional pleasure, surprise, admiration and comfort, even on a subconscious level. Impression marketing has developed gradually at the intersection of relationship marketing, event marketing (event marketing) and show marketing (entertainment marketing). At the same time, impression marketing requires a balanced, thoughtful and emotional approach from professionals, and the main tool of a marketer is an emotional analysis and the ability to think and feel the consumer (Barkov et al., 2020; El Issawi, 2021; Madani et al., 2021). 
In modern conditions, impression marketing is becoming not only one of the modern concepts of marketing, which is characterized by the latest technologies to influence consciousness, but also the modern idea of management and style of achieving the goal. The emotions lead to intermediate effects including the following: changes in attention; "shift" of social, informational, temporal and normative concentration and fixation; fluctuations in the level of citizens' confidence. It is emotions that influence making decisions because they adjust the sphere of attention, for example, positive emotions increase attention because they focus on abstract information and general principles (positive emotions signal a person about safety, security, satisfaction of his needs); negative emotions, on the contrary, narrow the attention, because people focus on the little things that demonstrate the instability of the situation. Emotions may influence making decisions because people focus on "information as mood" (personality state). It is interesting that emotions influence making decisions because they stimulate the degree of mental information processing (the ability to think). The factor influencing this process is level of human confidence, namely: emotions with a "deep degree of confidence" (anger); emotions with a "low degree of confidence" (fear) which lead to the systematic processing of information, when there is no confidence, and therefore, doubts about the decision are present.

As already mentioned, impression marketing is a tool for building an emotional connection between the producer of goods and the consumer (the electorate). The basis of emotional marketing is emotional intelligence and the ability to perceive feelings, generate them, and not only understand emotions, but also manage them. Emotional intelligence involves the ability to properly assess and influence the situation, intuitively feel what other people want, know their strengths and weaknesses, and be "charming, attractive, stress-resistant and adaptive" (Hobbs, 2021). In addition, emotional marketing is associated with the creation of positive associations, and this is a very complex creative process because people have different preferences that may change over time. It concerns emotional benefits, not the needs associated with a high degree of personification of marketing efforts to ensure the emotional marketing effect (Hobbs, 2021). There is a universal key to understanding the "satisfaction" of consumer emotions and it is the interrelation of expectation and result since marketing is designed to make a person happy. Marketers try to take into account all the wishes of consumers and emotional marketing makes it possible to win such a factor as sympathy, which is extremely important in the political sphere. In addition, in a competitive environment, marketers (especially political technologists) work with the audience attention.

The main purpose of the article consists of two tasks. The first one is to reveal the essence of emotional marketing, and the second one is to analyze the marketing of impressions as a tool for building direct emotional connections in the political sphere.

\section{Methods}

To achieve the goal of this study, the analysis of different views on the effect of emotion on human behavior was conducted. It can be stated that emotions affect human behavior by changing it, but they are also used to achieve the desired perception of decisions. There are three types of emotions that influence making decisions. Among them, there are integral emotions, which are directly related to decision-making. Random emotions are related to current mood, which people use to build thoughts, reasoning, judgments, and the political mood is an important tool for influencing the behavior of society. Situational or objective emotions have a differentiated orientation and suggest, convey and outline a person's attitude to a particular phenomenon (Petranova \& Rysová, 2020).

The R. Plutchik's (1970) approach is considered which consists in the idea that out of a large number of emotions, a person should choose one and, through appropriate technologies, work with it. Special attention was paid to approaches to the emotion of fear. The authors support the opinion that fear (the most important emotional state for politics), humiliation and hope are the emotions that determine the masses behavior. D. Moisi (2009) created the theory of mass emotions where a set of shades and halftones of fear, hope and humiliation becomes emotions culture.

Emotional marketing technologies intersect with technologies of event marketing, show marketing, advertising and PR. Such combination allows to unobtrusively get positive impressions, feelings, excitement, self-affirmation, self-expression for a long time, feel the significance of the "purchased product". Emotional marketing involves an in-depth analysis of the market, which takes into account the mood and emotional trigger of a person through previous experience; penetration into human needs and interests; ideas about the client's emotions; understanding of what is expected from them (Burukin et al., 2021). Emotional marketing technologies affect not only instant emotions but also works with a sense of nostalgia. That is, emotional marketing evokes a sense of change in time, which is reflected through the specific cultural codes and traditions that are different for each country (Moisi, 2009). In this context, the specifics of post-Maidan society were studied and Ukrainian post-Maidan realities were characterized for a more precise assessment of the Ukrainian electorate.

The analysis of the reaction of the population to the emotional style of communication of President V. Zelensky was conducted based on the research by O. Zlobina and Ye. Blyzniuk (2021). The data on basic and derivative emotions evoked by President Zelensky in the population was provided. 


\section{Results and Discussion}

The whole emotional sphere is inherent in politics and is its driving force and the motivational mechanism that manifests itself in the political activities of parties and leaders (Lebedynets \& Zhurakivska, 2021). Experienced marketers, especially in politics, "work" with basic emotions: fear, joy, sadness, surprise, anger, disgust (Rejkowski, 1968). Usually, emotions do not appear accidentally, they have certain causes and change according to certain rules, knowing which allows marketers to manage, recognize, interpret the relationship of emotions and behavior and reconstruct further development of emotional states.

However, "games" on emotions are not a Ukrainian trend, but a global one. If in the previous election campaigns the slogan of domestic politics was "vote with the heart", the motto of the last election campaigns was "let's create emotions together". Today, political technologists "trade" dreams, experiences and emotions, range from "Disneyland" to "selling" politicians. They are particularly engaged in emotionally profound influence on personality. In impression marketing technologies, the impact is directed at the subconscious, especially in the area where the product is filled with an emotional component: political show projects, which overwhelm the Ukrainian media sphere, image creation, advertising, Internet, PR (Tanrikulu, 2021).

Modern consumer of a political product is looking for an emotional component that would complement or fill the product with an additional effect, excite them. It is possible to capture the consumer's attention, to "surprise" them by offering extraordinary impressions, emotions, ideas, views, judgments (Burukin et al., 2021). People want to be entertained, so comedians (for example, D. Trump, V. Zelensky) are being elected presidents. That is, the electorate is not serious about everything and lives under the motto "everything that does not entertain us is uninteresting and boring". The key "traders" of emotions are TV people: owners of the media space, film actors, pop stars, athletes, celebrities, political experts, consultants, journalists, bloggers. In Ukrainian political realities, political experts, analysts, consultants, and political technologists cultivate and produce their stardom and recognition, creating ratings of media popularity and "throwing" it out on social networks. Therefore, modern politics is characterized by total "game" components of attraction, theatricality, entertainment, carnival and showmanship.

Special technologies of emotional marketing are such modern mechanisms that are related to social networks, virtual reality, receiving bonuses, the Internet, video content. It is especially important to evoke positive emotions, "bringing" emotional pleasure, surprise, admiration and comfort, even on a subconscious level. Therefore, if something emotional is imposed on the audience, it can be manipulative component of political technology. In this context, it is worth mentioning anti-advertising on social networks, which appeals to emotions. According to experts, emotions are a "lousy adviser", and to be guided by them when choosing the president, members of parliament is unacceptable (Hemker et al., 2021; Hobbs, 2021; Plutchik, 1970).

The "satisfaction" of consumer emotions can be understood as the relation between expectation and result. Marketers try to take into account all the wishes of consumers so that the emotional marketing makes it possible to win such a factor as sympathy. In addition, in a competitive environment, marketers, and especially political technologists, work with the attention of the audience. It is clearly reflected in the Ukrainian election campaigns (presidential - 2018, parliamentary - 2019 and local - autumn 2019) through the creation of an advertising product, because political advertising mobilizes political behavior by informing and stimulating certain emotional states. Political advertising, which is designed for human emotions, concentrates on the dynamic nature of slogans that help identify a person with a political entity. In particular, admiration / increased impulsiveness, interest / curiosity and an attractive story which is created with help of storytelling technology, feelings of happiness, use of negative emotions, hope for the best (election of the person voted for, awareness of pride leader), the state of urgency (proposal in time) - surprise / admiration, a sense of belonging to something / someone (increased motivation), guilt, awareness of importance / significance / value for others are all this affects the use of various technologies in emotional marketing (Madani et al., 2021).

In our opinion, the technology of emotional marketing in the political sphere is action management. Therefore, a special role in the political sphere is given to emotions as a result of assessing the situation: a person's assessment of opportunities, meeting their needs, which depend on internal conditions. An experienced person "connects" emotions with a specific political situation that they understand. Thus, according to the Polish scholar J. Rejkowski (1968), "the relationship between political events, the causal links between factors of ideological, social and economic nature, are so complex that their combination together exceeds the dilettante's capabilities". This situation contributes to the dominant emotional attitude to certain events. The modern Ukrainian political space is full of examples of the influence of emotions on politics, such as speeches by politicians, parliamentary sittings, hostage-taking, arrests and searches of businessmen, officials, individual politicians, and the undermining of political party headquarters (Bondarenko et al., 2021; Zlobina \& Blyzniuk, 2021).

For a large number of Ukrainians, the attitude to representatives of Ukrainian politics, from the first president of 
Ukraine to the last (L. Kravchuk, L. Kuchma, V. Yushchenko, V. Yanukovych, P. Poroshenko, V. Zelensky) is "emotionally charged". We mean such emotional states of people as interest, surprise, distrust, fear, anger, anxiety, shame, contempt or disappointment. But the emotions associated with unfulfilled expectations from presidential, parliamentary or local campaigns most often arise in Ukrainian society, especially in post-Maidan Ukraine. All, without exception, the presidents of Ukraine, in our opinion, have not left or will not leave Ukrainians indifferent to their personalities. One of the most emotionally charged political figures is the current President of Ukraine V. Zelensky. It is interesting that the emotional interaction with the electorate preceded its acquisition of official status and was built, during many years of its acting communication. This may be stated considering the series "Servant of the People", where the protagonist both in the series and in real life became president. The status has changed, but the emotional connection still remains one of the president's strengths. As an example, the president's New Year's greetings may serve, where there were more emotions than the official data.

We would like to offer research material of Gradus Research, which through an online panel by self-filling questionnaires in a mobile application conducted an analysis of the reaction of the population to the emotional style of communication of President V. Zelensky and show whether emotional contact remained strength of his communication. After evaluating the general perception of the president by the population, it can be stated that the basic emotions are expectations, surprise and sadness. Some participants considered themselves to be those who do not feel any emotions towards the president (Zlobina \& Blyzniuk, 2021). In particular, such emotions as vigilance, mistrust and hopelessness are felt by a third of respondents, and this, in our opinion, is evidence that part of the country's population is anxiously waiting. Interesting is the fact that negative emotions are felt by $35.8 \%$ of the population, shame - by $29.5 \%$, contempt - by $20.3 \%$. The figure of the president evokes positive emotions in only one-fifth of those polled. Research also showed that young people (aged 18-24) are mostly sympathizers of President V. Zelensky, while the older generation feels anxiety, distrust and annoyance from the president's actions. At the intersection of such emotional states, complex psychological feelings of the population towards politicians are formed (Armoudian \& Milne, 2021).

In addition, the perception of the president depending on the type of settlement was studied. It was found that people in small towns show negative emotions (hopelessness, indignation, vigilance). In general, the picture was varied and ambiguous, and to understand the emotional picture of the general emotional state of the population to the incumbent president, it is necessary to compare the data of those who voted for him and those who voted for his opponent. Among respondents, $48.9 \%$ voted for the incumbent president was and $28.8 \%$ voted for his opponent (Zlobina \& Blyzniuk, 2021).

Comparing the data, we can conclude that emotional feelings are almost polar (Figures 1,2); the only thing that unites the representatives of these groups in their attitude to the president is that he is not indifferent to them, but a split in the attitude of the population to the current president is clear. The emotional states of presidential voters shift from a weak range of feelings in the negative field to basic and heightened emotions in the positive field. Voters of the current president do not lose hope and are in a state of expectation, although a significant part (about 70\%) push the president away and hope for nothing (Zlobina \& Blyzniuk, 2021). There are some explanations for this: firstly, there is less and less hope for positive changes in the state's economic sphere; secondly, there is a combination of the president's lack of political and managerial experience, which does not affect the lack of reform of the entire management system. Also, some people consider video addresses of the president unusual. They play an important role in maintenance of emotional communication with the audience. The president's reaction to the quarantine measures (reaction to protests by small and medium-sized businesses) affects society’s opinion as well (Bondarenko \& Yesimov, 2021). 


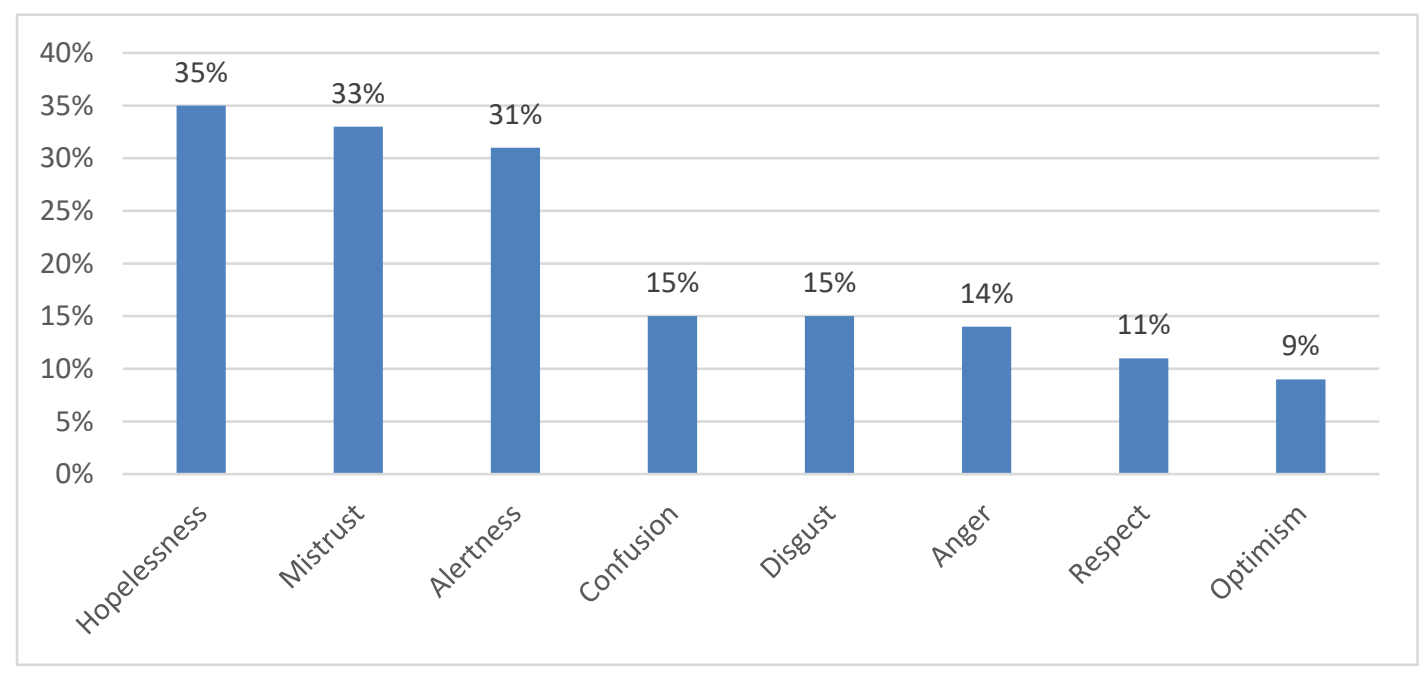

Figure 1. Basic emotions evoked by President Zelensky in the population

Source: Zlobina \& Blyzniuk, 2021

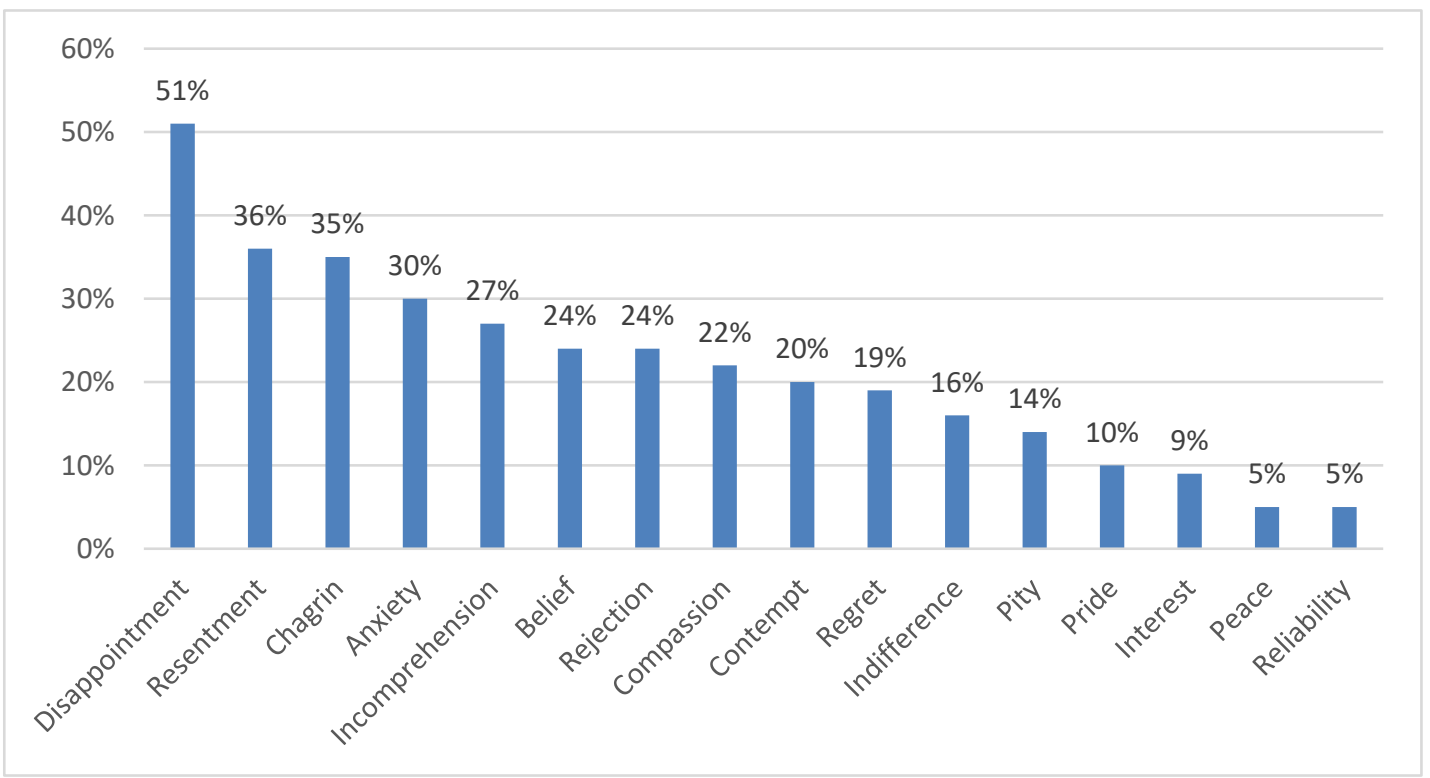

Figure 2. Derivative emotions evoked by President Zelensky in the population

Source: Zlobina \& Blyzniuk, 2021

A special place in the marketing of impressions as a tool for building emotional connections is taken by political sentiments (Zlobina \& Blyzniuk, 2021), in which society and political feelings are constantly present. Emotional marketing technologies affect instant emotions and they are successfully implemented into Ukrainian realia making impact on the feeling of nostalgia. Emotional marketing explains the feeling of time changing, which is reflected through the specific cultural codes and traditions. Therefore, in the Ukrainian post-Maidan realities, there is such a large number of nostalgic for the past population, which is a fairly high percentage of the electorate. Political sentiment is a multilevel structure that includes socio-political factors, their assessment and willingness to act. That is, political sentiments arise on the basis of the reaction to socio-political events, which we identified through the emotional state of the population.

That is, political sentiments can generate opposite movements (spontaneous, impulsive) and change the psychology of cohesion of certain groups in general. But political attitudes can be neutral (e.g., apathy, loss of interest in politics), positive (e.g., active participation in politics, enthusiasm, anticipation of election victory, heroism of certain individuals), and negative (which reflect inconsistencies in political expectations; this condition contributes to the conflicts development, leads to crises). In addition, negative attitudes can create political immobility (political passivity) in the population and indifference, political conformism, political boycott and lack of feeling that citizens will be realized, which can be observed in Ukrainian realities (Bondarenko et al., 2021). 
All political regimes try to predict the mood of the population, and thus, if necessary, to control it. For example, spreading myths or giving promises during elections is a kind of populism that has become a trend of many politicians not only in Ukraine. A clear example of the protest mood is the fact that a third of Americans voted for J. Biden in the election, guided by the protest mood against D. Trump (Scribano, 2021). A similar picture could be seen in the last presidential election in Ukraine since some people voted not so much for V. Zelensky as against P. Poroshenko.

As for political feeling, it is the emotional attitude of the individual to political processes. Political feelings are the greatest object of manipulation, because the feelings themselves are mobile and "pliable" and they easily change shape or are subject to certain actions. As Z. Bauman (2016) points out, it is best to persuade and conquer the masses not with facts (evidence) but with emotions. In the field of feelings, it is best to create a chain reaction of "infection" and an epidemic of feelings. Therefore, politicians (political technologists) "swing" the political sphere, for example, through the coverage of conflicts, political scandals, terrorist attacks. It should be noted that often, in order to "swing" the emotional sphere in the political sphere, crises are artificially created by anomalous, unusual situations (Hemker et al., 2021).

One of the dangerous feelings in the political sphere is fear which is a negative emotional process that motivates the behavior of the population and a tool of governance. Fear is a basic emotion that is associated with the threat of destruction and personal safety (for example, instilling fear through the coronavirus, and in the absence of objective, mobile and transparent information, this condition only intensifies, causing distrust of the ruling team). The primary way to manage fear is to have objective information. As J. W. Whitehead (2012) points out, fear evokes a policy of fear whose sole purpose is to disorient and divide society. Therefore, fear can be called the core of modern politics. The government either eliminates the feeling of fear, or vice versa - uses such an emotional state to consolidate their positions. In such cases, the state and its structures first impose various fears on society, and then act as the only legitimate force that can protect people and society as a whole. Under the pressure of fear, society can easily agree to any government measures for solving problems, sometimes even up to the restriction of their rights and freedoms.

It is fear that can reformat politics. According to P. Dutkevich and D. Kazarinova (2017), fear:

1) became a projection of political will that changes the existing order;

2) strengthens power relations, and thus forms a new political dogma / super-ideology;

3) generates alternative legitimacy for state power.

In this state of affairs, there is an order called "new regnum" which begins with "fear as a politician". That is, fear becomes the essence of modern politics, squeezing out all other sources of legitimation of power. In our opinion, the government is not trying to eliminate the causes of fear, but on the contrary, is using it to consolidate its pro-government positions. Fear-based politics is rooted in the political sphere of society through political parties and electoral politics. In modern Ukrainian realities, fear is a motivated, decisive emotion in the political sphere. Ukrainian society "feels" through the use of manipulative technologies by public authorities, various social fears such as fear of instability in society, fear of occupation of the state, of the threat of default, of economic crisis, job loss, rising prices, global financial crisis, accidents and disasters.

It is important to note that fear can also play a mobilizing role and be the center, the core of the viability of collective (social) renewal. For example, fear of aggression mobilizes people, which is demonstrated by the volunteer movement, that became an important, effective and influential component of civil society in the post-Maidan period (Scribano, 2021). All this contributes to the emergence of barriers to the image of the state, which "exposes" the problem fields of Ukraine. The problem field can be manifested in the slowdown in the particular social sphere development or in the deviation from the optimal path of its development, which can affect the risk of conflict in any area of society. It could be noted that a typical negative stereotype of Ukraine is endemic corruption, which belongs to the problem field of the state (Palacio et al., 2021). Based on the above, for the emotional marketing development and image of Ukraine, first of all it is necessary to establish an effective response and preventive measures for integrated risks for Ukraine (Bobrovska et al., 2020). In this case, it is about the problems of public administration, namely its inefficiency.

\section{Conclusions}

The modern political process is replete with examples of the influence of emotions on politics, although in Ukrainian political science the phenomenon of emotions and their effect on political processes has been insufficiently studied. Almost all episodes of politics are accompanied by emotional experiences. Emotions are manifested both during tragic events (wars, revolutions, cataclysms) and in peacetime. They are speeches by presidents, parliamentary debates, negotiations. Emotions are especially important in post-conflict societies and have a direct impact on political processes and the course of institutional reforms.

In general, under the influence of emotions a person quickly makes decisions and chooses those options that are 
"beneficial" or suits them. Emotions are reflected in decisions influencing the perception of values, the population has a sense of choice, forming the image of political leader, party, party, states at the international level. Based on analytical research, it is determined that emotions are an indicator of the political situation in the country. In modern Ukrainian realities, today fear is a motivated, decisive emotion in the political sphere. Ukrainian society "feels" through the use of appropriate technologies various social fears and anxiety of instability in society, threats of default, the onset of economic crisis and so on. It is important to note that fear can also play a mobilizing role and to be the center, the core of the collective (social) viability renewal (for example, fear of aggression mobilizes people).

Thus, impression marketing (emotional marketing) is a technology of promoting a political product, which is aimed at building an emotional connection. Impression marketing aims to force the electorate to accept the emotional connection between government and society. Addressing emotions, marketing impressions, adjusts and pushes the electorate to the emotional rhythm of information perception. The use of such technologies in the political sphere leads to "fear as politics".

\section{References}

Armoudian, M., \& Milne, B. (2021). The politics of blame: Mass media messages and political violence during peace negotiations. Journalism, 22(9), 2182-2202. https://doi.org/10.1177/1464884919860280

Barkov, S. A., Dorokhina, O. V., Markeeva, A. V., \& Maximov, A. A. (2020). Dynasties and brand names in the political sphere of the post-industrial society. RUDN Journal of Sociology, 20(4), 801-820. https://doi.org/10.22363/2313-2272-2020-20-4-801-820

Bauman, Z. (2016). Behind the world's crisis of humanity. Al Jazeera. https://www.aljazeera.com/program/talk-to-al-jazeera/2016/7/23/zygmunt-bauman-behind-the-worlds-crisis-of-hu manity

Bobrovska, O. Y., Drobot, I. O., Nadyuk, Z. O., Hrytsko, R. Y., \& Pokataev, P. S. (2020). Modern theories of public administration: Experience for Ukraine. Journal of the National Academy of Legal Sciences of Ukraine, 27(4), 107-120. https://doi.org/10.37635/jnalsu.27(4).2020.107-120

Bondarenko, S., Tkach, I., Drobotov, S., Mysyk, A., \& Plutytska, K. (2021). National resilience as a determinant of national security of Ukraine. Journal of Optimization in Industrial Engineering, 14(1), 111-117. https://doi.org/10.22094/JOIE.2020.677837

Bondarenko, V., \& Yesimov, S. (2021). Public opinion as an assessment criterion of the public administration activities. Social and Legal Studios, 4(14), 39-45. https://doi.org/10.32518/2617-4162-2019-1-39-45

Burukin, V., Vezlomtsev, V., Vezlomtseva, S., \& Zarubina, O. (2021). Correlation of social mechanisms of corruption and social climate. E3S Web of Conferences, 258, article number 05022. https://doi.org/10.1051/e3sconf/202125805022

Cervera, A., Mollá, A., \& Calderóoan, H. (2000). Market orientation: A framework for public institutions. Journal of Nonprofit and Public Sector Marketing, 7(1), 3-23. https://doi.org/10.1300/J054v07n01_02

Dutkevich, P., \& Kazarinova, D. B. (2017). Fear as a policy. Polis. Political Studies, 4, 8-21.

El Issawi, F. (2021). Media pluralism and democratic consolidation: A recipe for success? International Journal of Press/Politics, 26(4), 861-881. https://doi.org/10.1177/19401612211010480

Hemker, S., Herrando, C., \& Constantinides, E. (2021). The transformation of data marketing: How an ethical lens on consumer data collection shapes the future of marketing. Sustainability (Switzerland), 13(20). https://doi.org/10.3390/su132011208

Hobbs, J. (2021). Cosmopolitan sentiment: Politics, charity, and global poverty. Res Publica, 27(3), 347-367. https://doi.org/10.1007/s11158-020-09478-w

Lebedynets, I. S., \& Zhurakivska, Yu. M. (2021). Features of establishment and development of motivational culture at enterprises in modern economic conditions. Scientific Bulletin of Mukachevo State University. Series "Economics", 8(3), 93-101. https://doi.org/10.52566/msu-econ.8(3).2021.93-101

Madani, F., Seenivasan, S., \& Ma, J. (2021). Determinants of store patronage: The roles of political ideology, consumer and market characteristics. Journal of Retailing and Consumer Services, 63, article number 102691. https://doi.org/10.1016/j.jretconser.2021.102691

Moisi, D. (2009). Geopolitics of emotion: How cultures of fear, humiliation, and hope are reshaping the world. New York: Doubleday. 
Palacio, J. R. S., Climent, V. C., \& Catalá, A. E. (2021). The organizational model of the economy for the common good and its comparison with other approaches to sustainability. CIRIEC-Espana Revista De Economia Publica, Social y Cooperativa, 101, 143-163. https://doi.org/10.7203/CIRIEC-E.101.16399

Petranova, D., \& Rysová, A. (2020). Behavioural approaches in public policies. European Journal of Science and Theology, 16(4), 65-77.

Plutchik, R. (1970). Emotions, evolution, and adaptive processes. In M. B. Arnold (Ed.), Feelings and emotions (pp. 3-24). New York: Academic Press. https://doi.org/10.1016/B978-0-12-063550-4.50007-3

Rejkowski, J. (1968). Experimental psychology of emotion. Warszawa: KiW.

Scribano, A. (2021). Colonization of the inner planet: 21st century social theory from the politics of sensibilities. New York: Routledge. https://doi.org/10.4324/9781003170662

Tanrikulu, C. (2021). Theory of consumption values in consumer behaviour research: A review and future research agenda. International Journal of Consumer Studies, 45(6), 1176-1197. https://doi.org/10.1111/ijcs.12687

Whitehead, J. (2012). The politics of fear in America: A nation at war with itself. The Huffington Post. http://www.huffingtonpost.com/john-w-whitehead/politics-of-fear-america_b_1922963.html

Zlobina, O., \& Blyzniuk, Y. (2021). What emotions does the president evoke in Ukrainians? Gradus Research Website. https://gradus.app/documents/48/President_Emotions.pdf

\section{Copyrights}

Copyright for this article is retained by the author(s), with first publication rights granted to the journal.

This is an open-access article distributed under the terms and conditions of the Creative Commons Attribution license which permits unrestricted use, distribution, and reproduction in any medium, provided the original work is properly cited. 